\title{
Hypertension and Pharmacological Therapy in Women
}

\section{Elisa Lodi, Alberto Carollo, Valentina Martinotti \& Maria Grazia Modena}

High Blood Pressure \& Cardiovascular Prevention

ISSN 1120-9879

High Blood Press Cardiovasc Prev DOI 10.1007/s40292-018-0257-0

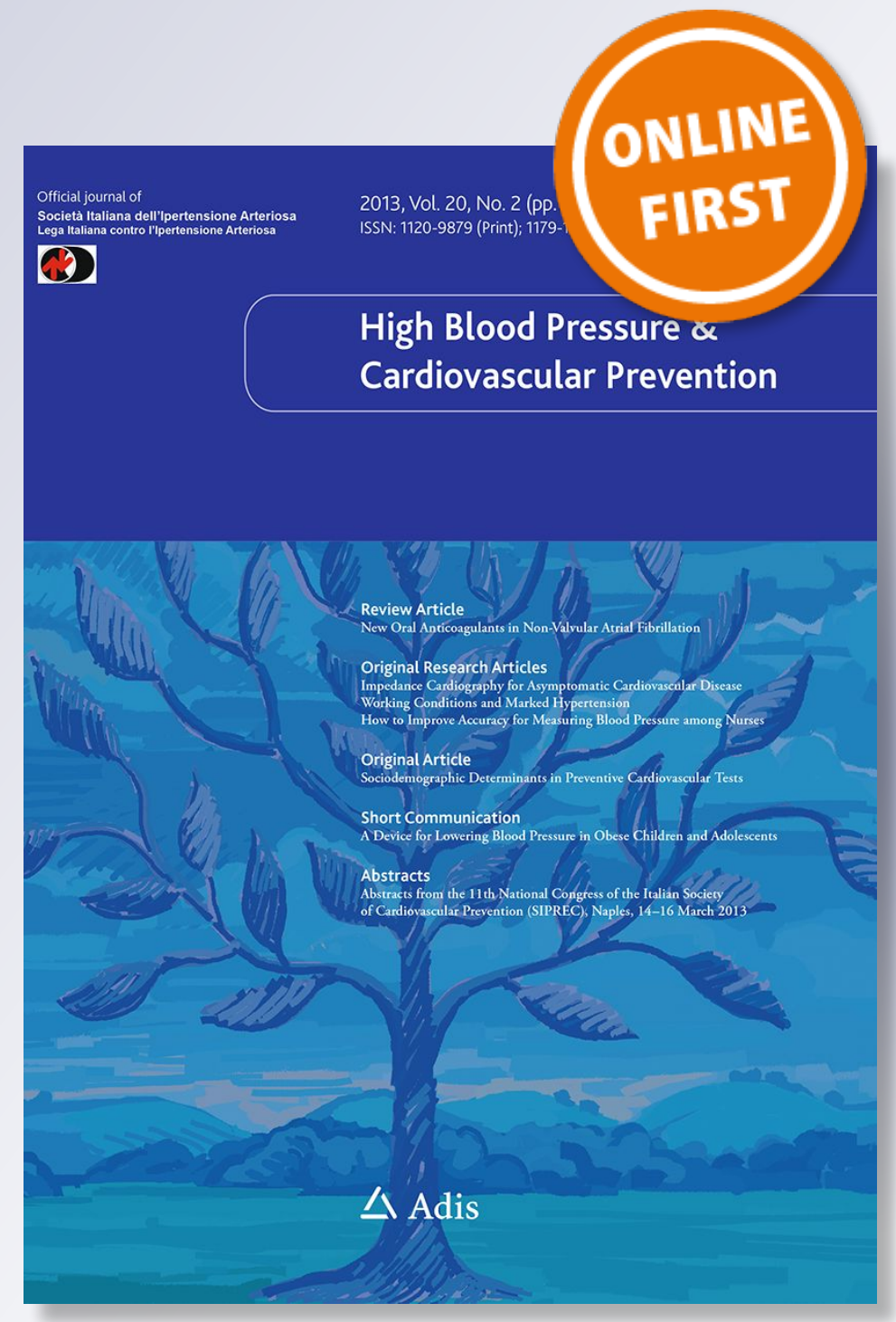

是 Springer 
Your article is protected by copyright and all rights are held exclusively by Springer International Publishing AG, part of Springer Nature. This e-offprint is for personal use only and shall not be self-archived in electronic repositories. If you wish to self-archive your article, please use the accepted manuscript version for posting on your own website. You may further deposit the accepted manuscript version in any repository, provided it is only made publicly available 12 months after official publication or later and provided acknowledgement is given to the original source of publication and a link is inserted to the published article on Springer's website. The link must be accompanied by the following text: "The final publication is available at link.springer.com". 


\title{
Hypertension and Pharmacological Therapy in Women
}

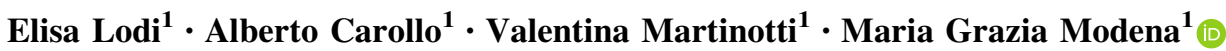

Received: 26 February 2018/ Accepted: 21 March 2018

(C) Springer International Publishing AG, part of Springer Nature 2018

\begin{abstract}
Cardiovascular (CV) disease is the leading cause of morbidity and mortality for women all over the world. The role and weight of risk factors in relation to gender are not completely clarified as well as their treatment. Pathophysiology of hypertension in woman presents different aspects in relation to phase of life, with an impact on treatment. The only certainties that we have nowadays regarding hypertension therapy in women are really few and may be summarized in: how to treat or, better, what not to use in hypertension in pregnancy and how to treat acute severe hypertension in pregnancy. We have some certainties also on treatment of hypertension associated to some women's comorbidities. Considering guidelines and analyzing what happens in the real world, we report in this review that women have similar major $\mathrm{CV}$ risk factors of men, although a minor CV global risk. However, there are some data that suggest that hypertension and diabetes are more important risk factors in women than in men. Blood pressure reduction and benefit by treatment appear similar in women and men, suggesting that we should aim for similar target of blood pressure, although the lower global risk profile should imply different target. Theoretically, recommended drugs are similar in women and men, but in women we must take in account $\mathrm{CV}$ risk profile, comorbidity, side effects, and reproductive health. Finally, registries and observational studies show that fewer women reach the target values of blood pressure and that women receive more frequently prescription of "other" classes of drugs than those recommended by guidelines, even after normalization by age and comorbidities.
\end{abstract}

Maria Grazia Modena

mariagrazia.modena@unimore.it

University of Modena and Reggio Emilia, Modena, Italy
Keywords Hypertension - Gender medicine - Women · Anti-hypertensive drugs

\section{Introduction}

Cardiovascular (CV) disease is the leading cause of morbidity and mortality for women all over the world. The role and weight of risk factors in relation to gender are not completely clarified as well as their treatment, except for lifestyle's modification which is the common soil either in men as well as in women for first pass therapy of all diseases. Guidelines do not clearly identify differences in relation to gender, but the therapeutic response depends on the interaction between genes, environment and culture; therefore, it is important to define the concepts of sex and gender. Sex includes everything related to biology (genes, hormones, etc.), while the concept of gender, brought to the biomedical and human sciences, includes cultural, environmental and social influences [1]. In particular, pathophysiology of hypertension in women presents different aspects in relation to phases of life, with an obvious impact on treatment. This does not happen in men, who nevertheless have always been enrolled in a much larger number in clinical trials.

\section{Do We Have Certainties on Pharmacological Therapy in Women?}

The only certainties that we have nowadays regarding hypertension therapy in women are really few and may be summarized in: how to treat or, better, what not to use in hypertension during pregnancy and how to treat acute 
(severe) hypertension in pregnancy. These issues are discussed in other chapters of the present volume. We have some certainties also on treatment of hypertension associated to some women's comorbidities as thiazide use and risk for osteoporotic fractures among hypertensive patients. For example, the Swedish primary Care Cardiovascular Data-base (SPCCD) clearly demonstrated their efficacy on fractures during 7 years of follow-up [2]. Finally, we know that isolated systolic hypertension is more frequent in elderly women and that its treatment is often associated with orthostatic hypotension, caused or exacerbated by a list of well-known drugs (Table 1).

There are otherwise only general recommendations deriving from observations in literature [3] and different guidelines $[4,5]$ (Table 2).

There are also general recommendations deriving from different guidelines:

- major risk factors for cardiovascular complications in women and men are similar.

It is usually reported that major risk factors for cardiovascular complications in women and men are similar and if we use the algorithms, like the SCORE Chart [5] or Framingham index [6], we usually consider the same risk factors: smoking, age, blood pressure, cholesterol. So major risk factors are the same. Although if we observe either the score and the index in relation to risk factors and sex, we clearly derive that the overall cardiovascular risk in women is lower. However, there are some data that suggest that blood pressure as a risk factor is more important for cardiovascular events in women than in men, but in men atherosclerotic process is more important. Diabetes of course confers high risk for cardiovascular complications, but it confers a greater risk in women than in men. As we mentioned, there are lower global cardiovascular risk profile in women and we know that the reproductive history complications during pregnancy is relevant, and obviously in women. So major risk factors are similar, but they are not the same.

There are otherwise only commonly quoted general recommendations deriving from different guidelines:

- similar blood pressure reduction by treatment are important either in women as in men

- similar benefits are obtained by treatment in women and men.

It is reported that similar blood pressure reduction by treatment should be used in women and men, and it is stated that similar benefit by treatment is apparent in women and men and thus we should have similar target blood pressure in women and in men if the risk is the same and the benefit is the same. First of all, there are very few studies on outcome in women treated for hypertension. Many studies include women and the trend is positive but still the inference is that we study effects on the population and we see that there is an interaction between women and men and outcome, and very few showed effects of antihypertensive treatment in women alone [7]. So, the knowledge is insufficient, at least in our opinion.

We can have some help by using meta-analysis, such as that one by Turnbull et al. [8], published almost 10 years ago, where, in the "The blood pressure lowering treatment trialists' collaboration" they put together the effects of hypertensive treatment in women and men analyzing patient's data from 31 randomized controlled trials on blood pressure lowering agents including (but not limited to) hypertension. The total number of patients was 87,349 women and 103,268 men, in trials published in 1995 or later. Proportion of women was 47 (range 11-67)\%, mean age was 63 and 62 years in women and men, respectively and mean follow up was 2.6-8.2 years. If we use this kind of meta-analysis, we can see that coronary heart disease is

Table 1 Drugs associated with orthostatic hypotension

\footnotetext{
Examples of drugs that can cause or exacerbate orthostatic hypotension in women

Alpha-blockers: doxazosina (eg.)

Antidepressant drugs: selective serotonin receptor reuptake inhibitors, trazodone, monoamine oxidase, inhibitors, tricyclic antidepressants

Antihypertensive drugs: sympathetic blockers (eg.)

Antiparkinsonism drugs: levodopa, pramipexole, ropinirole (egs.)

Antipsychotic drugs: olanzapine, risperidone (egs.)

Beta-blocker drugs: propranolol (eg.)

Diuretic drugs: hydrochlorothiazide, furosemide (egs.)

Muscle relaxant drugs: tizanidine (eg.)

Narcotic analgesic drugs: morphine (eg.)

Sedatives/hypnotic drugs: temazepam (eg.)

Vasodilator drugs: hydralazine, nitroglycerin, calcium channel blockers (egs.)
} 
Table 2 Commonly quoted general recommendations deriving from different guidelines

\author{
Major risk factors for cardiovascular complications in women and men are similar \\ Similar blood pressure reduction by treatment are important either in women as in men \\ Similar target blood pressure values are valid for women and men \\ Similar drug classes should be recommended for the treatment of hypertension in women and men
}

more prevalent in men than in women, again supporting that atherosclerosis is more important in men, and major cardiovascular disease and mortality again is higher in men than in women. In this analysis they compared different drug classes, drug classes vs placebo, and also different doses of the same drugs. And if we compare differences in blood pressure reduction between women and men in the same studies by enlarge blood pressure, it seems to be reduced to similar degree both in women and as in men. So, this may suggest that blood pressure lowering treatment reduces blood pressure to similar degree in women and men. Looking afterwards to composite outcomes (major cardiovascular events) by comparing ACE inhibitors vs placebo, male and female, calcium antagonists vs placebo, and more vs less intensive treatment, benefits seems to be similar between women and men for all these three comparisons. Looking moreover for ARBs vs. placebo or for comparisons between ACE inhibitors, calcium blockers vs beta-blockers, or ACE inhibitors vs calcium antagonists, again blood pressure reduction by enlarge seems to be similar as well as outcomes in women and men. So, we could derive that there is theoretically support to suggest that blood pressure reduction by treatment is similar in women and men. The benefit in terms of relative risk reduction seems to be similar in women and men and therefore also same target blood pressure should be obtained. However, the total risk is lower in women, then the doubt remains that it would be logical for women to have higher blood pressure target than men.

There are otherwise only commonly quoted general recommendations deriving from different guidelines:

- similar drug classes should be recommended for the treatment of hypertension in women and men.

The very well done meta-analysis by Turnbull et al. [8] would lead us to assert that we should use similar drugs classes with evidence derived from large clinical trials, both in women and men. There are nevertheless side effects much more common in women. First of all, from airways by Ace inhibitors and we know moreover that asthma is more frequent in young women and chronic obstructive pulmonary disease (COPD) in the elderly. This allow us to say that ACE inhibitors are not preferred in women with COPD or asthma, because of the risk of side effects. Swollen ankles from calcium antagonists are more common in women than in men, that maybe an argument to favor diuretic therapy in women, although diuretics generally are not able to solve the problem. Sometimes alphablockers also, which have a strong indication in hypertensive men with prostatic problems, induce swollen ankles in women, but the association with diuretics may cause severe hypotension. Another gender related difference with impact on pharmacological treatment is the prevalence in women of comorbidities, such as autoimmune diseases. Women attempt primary care more often for inflammatory disease and pain, they consume more steroids and nonsteroid anti-inflammatory drugs, which may counteract anti-hypertensive therapy because of possible side-effects on the.

Finally, postmenopausal status is associated with a $60 \%$ increased risk of metabolic syndrome (MS) and another cause of hypertension in post-menopause is obesity [9]. Hypertension associated with MS has a more severe cardiovascular risk and the response to therapy is less favorable than the isolated form of hypertension. This effect is due to MS-induced systemic endothelial dysfunction and chronic subclinical inflammation, factors that are recognized as powerful risk factors for cardiac and cerebrovascular events [10].

Data from our group demonstrated many years ago that the number of antihypertensive drugs used to maintain blood pressure in the normal range $(<140 /<90 \mathrm{mmHg})$ was on average higher in hypertensive women with MS $(4.5 \pm 1)$ versus hypertensive women without MS $(3.5 \pm 1 ; \mathrm{P}<0.05)$. The principal treatment was ACE inhibitors and ARBs. In particular, hypertensive women with MS, antihypertensive the treatment produced a more modest improvement of both endothelial dysfunction and subclinical inflammation comparing to the other group [11]. In the real word nevertheless, these commonly quoted general recommendations deriving from different guidelines do not appear totally confirmed.

Data from the International Survey Evaluating Microalbuminuria Routinely by Cardiologists in patients with Hypertension (I-SEARCH) [12] report gender disparities in antihypertensive drug usage and blood pressure (BP) control. The survey included 18,017 patients with hypertension and the study was conducted between September 2005 and March 2006 in 26 countries, collecting data on patient demographics, cardiovascular disease and risk factors, blood pressure, and cardiovascular drug treatment were collected. Mean systolic blood pressure 
(SBP) was $2.1 \mathrm{mmHg}$ higher in women $(150.6+/-$ $0.35 \mathrm{mmHg}, \mathrm{n}=8357 / 18,017)$ than in men $(148.5+/-$ $0.35 \mathrm{mmHg} ; \mathrm{P}<0.0001, \mathrm{n}=9526 / 18,017)$, whereas no difference in diastolic BP was seen $(88.2+/-0.20$ vs $88+/-0.20 \mathrm{mmHg} ; \mathrm{P}=0.198)$. Gender differences in SBP were more pronounced in diabetic as compared with non-diabetic patients $(3.5$ vs $1.7 \mathrm{mmHg}, \mathrm{n}=4272$ vs $\mathrm{n}=13611 ; \mathrm{P}<0.0001)$ and became evident at age of 55 years old. Overall BP-control rate was $33.6 \%$ in men and $30.6 \%$ in women $(\mathrm{P}<0.0001)$ and was lower in diabetic as compared with non-diabetic patients. In all, $30 \%$ of patients used one, $40 \%$ used two and $30 \%$ used $>$ or $=3$ drugs without gender differences. Response rates to different drug regimens appeared to be similar. However, women received more frequently thiazides and betablockers, and less frequently ACE-inhibitors as monotherapy.

\section{Conclusions}

Women have similar major CV risk factors (albeit, lower global CV risk) as men, but blood pressure and diabetes may have greater impact; we should consider also reproductive history in women. Blood pressure reductions and benefits by treatment appear similar in women and men in relative terms, suggesting that we should aim for similar target pressure, although the lower global risk profile should imply different target. Recommended drugs should be similar in women and men, but we must take in account $\mathrm{CV}$ risk profile, comorbidity, side effects, and reproductive health. However, registries and observational studies show that fewer women reach the target values of pressure and that women are more frequently prescribed "other" classes of drugs, even after normalization by age and comorbidities. There is room from improvement and this will likely provide major clinical benefit, equal for men and women.

\section{Compliance with Ethical Standards}

Conflict of interest On behalf of all authors, the corresponding author states that there is no conflict of interest.
Ethical approval This article does not contain any studies with human participants or animals performed by any of the authors.

\section{References}

1. Legato MJ, editor. Principle of gender-specific medicine—-gender in the genomic era. 3rd ed. New York: Elsevier; 2017.

2. Bokrantz T, Ljungman C, Kahan T, Schioler L, et al. Thiazide diuretics and fracture-risk among hypertensive patients. Results from the Swedish Primary Care Cardiovascular Database (SPCCD). J Hypertens. 2015;33(e Suppl 1):e94-5.

3. Muiesan ML, Salvetti M, Rosei CA, Paini A. Gender differences in antihypertensive treatment: myths or legends? High Blood Press Cardiovasc Prev. 2016;23(2):105-13.

4. $2013 \mathrm{ESH} / \mathrm{ESC}$ Guidelines for the management of arterial hypertension: the Task Force for the management of arterial hypertension of the European Society of Hypertension (ESH) and of the European Society of Cardiology (ESC). Eur Heart J. 2013;28:2159-219.

5. European Guidelines on cardiovascular disease prevention in clinical practice: The Sixth Joint Task Force of the European Society of Cardiology and Other Societies on Cardiovascular Disease Prevention in Clinical Practice. Eur Heart J. 2016;37(29):2315-81.

6. Mahmood SS, Levy D, Vasan R, Wang TJ. The Framingham Heart Study and the epidemiology of cardiovascular disease: a historical perspective. Lancet. 2014;383(9921):999-1008.

7. Ljungman C, Mortensen L, Kahan T, Manhem K. Treatment of mild to moderate hypertension by gender perspective: a systematic review. J Womens Health (Larchmt). 2009;18(7):1049-62.

8. Turnbull F, Woodward M, Neal B, Barzi F, et al. Do men and women respond differently to blood pressure-lowering treatment? Results of prospectively designed overviews of randomized trials. Eur Heart J. 2008;29(21):2669-80.

9. Roka R, Michimi A, Macy G. Associations between hypertension and body mass index and waist circumference in U.S. adults: a comparative analysis by gender. High Blood Press Cardiovasc Prev. 2015;22(3):265-73.

10. Leuzzi C, Modena MG. Hypertension in postmenopausal women. Pathophysiology and treatment. High Blood Pressure Cardiov Prev. 2011;18(1):13-8.

11. Rossi R, Nuzzo AC, Origliani G, Modena MG. Metabolic syndrome affects cardiovascular risk profile as response to treatment in hypertensive postmenopausal women. Hypertension. 2008;52(2):865-72.

12. Thoenes M, Neuberger HR, Volpe M, Khan BV. Antihypertensive drug therapy and blood pressure control in men and women: an international perspective. J Hum Hypertens. 2010;24(5):336-44. 